\title{
Exploring the role of anticipated emotions in product adoption and usage
}

\author{
Debora Bettiga ${ }^{1}$, Lucio Lamberti ${ }^{2}$ \\ ${ }^{12}$ Department of Management, Economics and Industrial Engineering, Politecnico di Milano, \\ Milano, Italy \\ ${ }^{I}$ Corresponding author: debora.bettiga@polimi.it; 2 lucio.lamberti@polimi.it
}

\begin{abstract}
Purpose - The study explores the role of positive and negative anticipated emotions on adoption and continued usage of consumer products. The components of value eliciting anticipated emotions are investigated as well.

Design/methodology/approach - The conceptual model proposed is tested in two empirical studies, one focusing on functional and hedonic products and one on incremental and radical product innovations. Data are collected through online surveys on consumers and are analysed using Structural Equation Modeling.
\end{abstract}

Findings - Results confirm the ability of anticipated emotions to influence product decisionmaking process. Moreover, anticipated emotions mediate the influence of value perceptions on product attitude. Findings show that these relationships vary greatly between initial adoption and further usage of the product.

Practical implications - Findings from this study may help marketers in the development of the right brand strategies and communication campaigns, aimed at building emotional connections with the consumer which prompt product adoption and usage.

Originality/value - Anticipated emotions, the predictions about the emotional consequences of a behaviour, have been acknowledged as strong drivers of consumer choices. Despite that, the role of anticipated emotions in product decision-making has not been explored yet. The present 
research, by means of a novel conceptual model, uncovers the role of anticipated emotions in both product adoption and continued usage decisions and depict the components of value arousing such anticipated emotions.

Keywords Attitude, Anticipated emotions, Product adoption and usage, Value perception

\section{Introduction}

In the last decade, a growing number of Companies have placed their marketing budgets in communication activities devoted to associate their products with emotional content. Several famous brands have built an emotional aura around themselves. For instance, Apple, through its commercials, sells a feeling of love, belonging and connectedness. Coca-Cola strongly identifies with the idea of happiness. Facebook builds on friendship. KFC, according to its marketing Chief David Timm "is now looking to connect with consumers on an emotional level rather than appeal to the rational side of their brain". How do these efforts, aimed at building emotional connections with the brand, affect consumer choices? Extant research does not answer this important question satisfactorily. Research in marketing, indeed, mostly focuses on emotions generated during the product interaction and, more generally, during the consumer experience with the product (Desmet \& Hekkert 2007; Gillison et al. 2016; Norman 2004; Mora \& Moscarola 2010). Hence, the kind of experience consumers have when they try the product in a shop or once they purchase the product and can actually use it. However, little is known on how emotions influence consumer choices on a prefactual basis, such as before the direct experience with the product. However, when consumers make decisions about product initial adoption, it is likely they imagine the emotions they might experience as a result of their choice (e.g. using this new car will make me excited). Similarly, it is plausible that the decision about 
the prolonged use of a product is influenced by the anticipated emotional consequences of its use in the future (e.g. using my car in the future will make me glad).

Research in psychology and related disciplines has demonstrated that the emotional consequence of a decision is anticipated by consumers and it is relevant in making the choice (Zeelenberg et al. 2000; Elgaaied 2012) confirming that emotions can be generated by appraising processes. Consumers may savour the anticipated pleasure connected with attaining something desirable, leading to more favourable attitudes and evaluations of the consumption experience (Coary \& Poor 2016). However, to the best of our knowledge, there is no research to date that investigates the role of these anticipated emotions in decision-making about products. Prior studies conducted on the process of emotional appraisal of future decisions mainly focused on contexts of uncertainty or risk, such as anticipated emotions of gambling or regret (e.g. Coricelli, Dolan, \& Sirigu, 2007). Other studies have been conducted on anticipated emotions as antecedents of personal goal desire, such as losing weight or obtaining a tenure position (Perugini \& Bagozzi 2001). The aim of this work is to explore the role of anticipated emotions on product adoption and usage. The first contribution of this work is to fill an important gap in research by investigating the influence of anticipated emotions on the continued use of products that have already been adopted, in addition to those being considered for adoption. The second contribution is the examination of the components of value that influence anticipated emotions, namely purposive value, usability, monetary value, social enhancement, interpersonal interconnectivity, entertainment value and self-discovery value. By doing that, our research contributes to high level of theory building by analysing a previously unexplored process, (value perceptions $\rightarrow$ anticipated emotions $\rightarrow$ attitude) and depicting the moderating role of product ownership (i.e. adoption versus continuous usage) into the process. The influence of attitude on intention to adopt/use (attitude $\rightarrow$ intention to 
adopt/use), largely confirmed in prior research (Fishbein \& Ajzen 1975), is empirically assessed in this research as well.

\section{Anticipated emotions and attitude}

Frijda argued that behaviour "can be motivated by the anticipation of emotion that could or will occur" (1986, p.187). Research confirmed that effortful decision making involves affective processes and elicits forward-looking anticipated emotions (Bagozzi \& Baumgartner 2000; Perugini \& Bagozzi 2001). Anticipated emotions have been defined as prefactual appraisals in which a subject imagines the affective consequences of goal attainment and goal failure before deciding to act (Gleicher \& Boninger 1995). Anticipated emotions can assume both a positive (e.g. excitement, delightfulness) and a negative (e.g. frustration, sadness) connotation not simply representing bipolar extremes of a single construct but structurally distinct constructs (Bagozzi et al. 1999; Phillips \& Baumgartner 2002). Positive anticipated emotions, indeed, represent the positive feelings arising from the possibility to achieve a goal in the future. Negative anticipated emotions, instead, represent the negative feeling generated by the impossibility to achieve a goal in the future. Thus, the more intense are the positive anticipated emotions (PAE) and the negative anticipated emotions (NAE), the more consumers are motivated to adopt behaviours needed to achieve the positive outcome or to avoid the negative consequence of their actions (Perugini \& Bagozzi 2001). In a similar vein, we assume that the same mechanisms will apply in the decision about product adoption and usage. If a consumer imagines that using a specific product will make him happy, he will be more likely to do so, to experience the positive outcomes of usage. Similarly, if he imagines that not using the product will make him sad or frustrated, he will be more likely to use it in the future, to avoid the negative feelings associated with privation of the product.

It is necessary to note that anticipated emotions alone do not predict action as they focus on the goal achievement feelings. Being affective responses they are integrated into the evaluative 
judgment. Attitude represents this evaluative response, the deliberative and cognitive judgement. It refers to an individual's enduring favourable or unfavourable evaluations of an object (Fishbein \& Ajzen 1975) that arises from beliefs, feelings, and behavioural inclinations towards the product and its meanings (Vaughan \& Hogg 2005). Research confirmed that mental imagery or mental simulation is enough to activate cognitive processes (Krishna 2012) and affect can determine more positive brand attitudes (Batra \& Stayman 1990; Holbrook \& Batra 1987). Attitude, in its turn, reflects the reasons for acting, the means to attain a goal: a positive attitude toward a product increases the intention to use it in the future (Davis 1989). The utility of the attitude concept rests, indeed, on the assumption that attitude influences behaviours, as Fishbein and Ajzen (1975) famously proved. Following this reasoning, we assume that both positive and negative anticipated emotions positively influence the attitude toward a product. Attitude, in its turn, determines intention to adopt or use the product in the future. Additionally, product nature may operate as a moderator, by interacting with antecedent constructs to influence decision-making outcomes. More specifically, as prior studies argue, hedonic and functional products may elicit different emotional responses and thus affect attitude differently (Kempf, 1998). More formally:

H1: Positive anticipated emotions, toward future product usage, positively influence attitude;

H2: Negative anticipated emotions, toward future product privation, positively influence attitude;

H3: Attitude positively influences intention to use;

\section{Value perceptions}

Emotions are influenced by the subjective cognitive evaluations of the product features and meanings (Lazarus 1991). Prior work confirmed that emotions are directly generated by the processing of understanding of products and their characteristics (Norman 2004). Physical 
product attributes, such as symmetry or beauty, can generate an aesthetic response of pleasure, while usability can generate relaxation. The emotional responses may be elicited by the interpersonal relationship a product enables (socio-pleasures), the product usefulness and ability to generate self-learning (ideopleasure) or the ease to use, the physio pleasure (Jordan 2002). Even objective product information like the price (Plassmann \& O’Doherty 2008) spur emotional responses, such as when a consumer is pleased or even excited after obtaining a good bargain. To understand the value perceptions arising from a product we draw upon the Uses and gratification paradigm, initially conceived for communication studies (Flanagin \& Metzger 2001) and further developed by Dholakia, Bagozzi, \& Pearo (2004). The theory accounts for the multiple uses different products enable. It proposes (Dholakia et al. 2004) five productrelated values: purposive value, connected to task achievement and instrumental objectives; entertainment value, mirroring fun and relaxation; self-enhancement, reflecting the pressure of social groups and the improvement of one's social status within his community; interpersonal interconnectivity, reflecting the social benefits deriving from interactions with other people; self-discovery, that involves the understanding and deepening of salient aspect of one's self through the elaboration of one's tastes, preferences and values. For consumer products, two additional value perceptions may be relevant: usability and monetary value. Usability is strictly related to the ease of use of the product (Davis 1989). Simplicity and immediate understanding are essential characteristics the consumer looks at and can shape the feelings toward the product. Monetary value becomes relevant for consumer products, as individuals face the monetary cost of product adoption and usage (Overby \& Lee 2006; Pontiggia \& Virili 2010). Following the discussion we propose:

H4: Value perceptions positively influence anticipated positive emotions;

H5: Value perceptions positively influence anticipated negative emotions;

\section{Adoption versus continuous usage}


Anticipated emotions are not permanent over time, but they are dynamic responses to imagined feedbacks and are contingent to the evaluation process (Bagozzi et al. 2003). Yogasara and Popovic (2011) investigated anticipated user experience by asking participants to imagine an interactive product and anticipate their experiences and feelings with it. They found that while positive anticipated user experience is related to an imagined product, a negative anticipated user experience is principally related to existing products. Similarly, Bagozzi and Lee (1999) sustain that emotional acceptance of innovations comes from positive emotions such as joy, pride, hope, love or liking while emotional resistance to innovations comes from negative emotions such as anger, fear, sadness and disgust, guilt, shame, contempt, and envy and jealousy. In a similar vein, we assume that anticipated positive emotions become relevant in influencing product adoption decisions. However, once the consumer holds and uses a product, habit becomes prominent in spurring further usage, thus motivational factors and related positive emotions likely decrease in relevance. Research, indeed, shows that the stronger the habitual use of a system, the less conscious planning is involved, and the relationship between subjects' evaluations of the system and their intention to use wanes (Wu \& Kuo 2008).

Conversely, we assume negative anticipated emotions may not be relevant in adoption decisions as it may be hard for consumers to judge the negative consequences of privation for products they do not own. However, as the product becomes part of the consumer daily life and generates functional dependence, the idea of not using it in the future may generate negative anticipated emotions. Habit, indeed, leads to resistance to innovations (Bagozzi \& Lee 1999). Individual's perceptual and cognitive mechanisms, such as attitude strength toward the object of habit, are likely to be tuned in to preserve the habit (Sheth 1981). Strong attitudes toward existing objects contribute to resistance to change and may prevent consumers from being open to innovations (Bagozzi \& Lee 1999). Thus, we assume: 
H6: The impact of anticipated emotions on attitude changes between adoption and continuous usage;

Value perceptions are not stable but can change in relevance over time, thus pre-adoption value perceptions do not predict post-adoption use consistently (Karahanna et al. 1999). This temporal dependence of the experience has three causes: an increasing familiarity with the product, functional dependency and hedonic attachment (Karapanos et al. 2009). Some researchers suggest that pragmatic aspects are the primary determinants of satisfaction during the first experiences with a product, but over time user identification, representing what the product expresses about its owner, become a more prominent aspect (Karapanos, 2013). Conversely, other studies found that usefulness (Kujala, Roto, Väänänen-Vainio-Mattila, Karapanos, \& Sinnelä, 2011) and ease of use (Mendoza \& Novick 2005) improve over time. Existing research does not agree on the influence of hedonic aspects as well. Karapanos (2013) suggests that the importance of product novelty and social meanings fast disappears over time, while different typologies of hedonic pleasure became relevant. Wilamowitz-Moellendorff, Hassenzahl, \& Platz (2006) found, conversely, that the perceived product arousal and pleasure became irrelevant over time. Thus, prolonged use seems to be spurred by different qualities than the ones that provide positive initial experiences (Karapanos et al., 2009). Following this discussion, we acknowledge the possibility that some value perceptions can decrease in effect to the level of irrelevance over time, and thus may play a role in product adoption only. Conversely, some value perceptions may be relevant for continuous usage decisions only. In the pursuit of simplicity, we prefer to formulate our research hypotheses symmetrically. Thus: H7: The influence of value perceptions on anticipated emotions changes between adoption and continuous usage.

Figure 1 presents the conceptual model proposed. 
Figure 1. Conceptual model

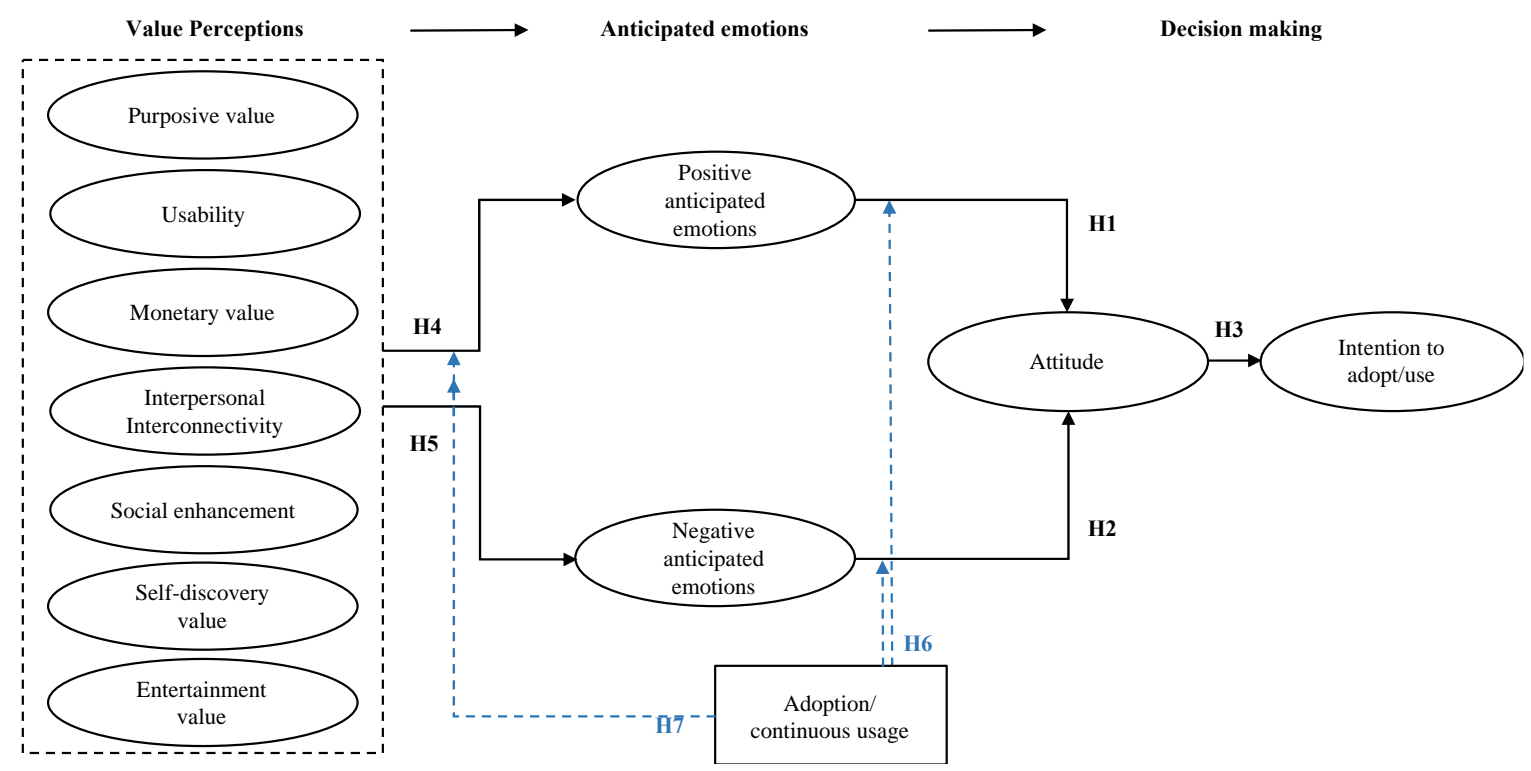

We tested our hypotheses across two studies, using general population samples and survey method. Study 1 tests the hypothesised relationships for two product typologies, functional products, serving primarily utilitarian and instrumental purposes and hedonic products, mainly satisfying entertainment needs, providing sensory gratification and fun (Holbrook \& Hirschman 1982). According to prior studies, indeed, emotional responses may be processed differently by consumers according to the mainly hedonic or functional nature of the product they are evaluating (Kempf \& Smith 1998; Batra \& Ahtola 1991; Chaudhuri et al. 2010). Study 2 replicates Study 1 by testing the psychological mechanism using different experimental stimuli, namely products representing a radical innovation and products representing an incremental innovation. We define a radical innovation a product that arises from a new technology and new knowledge and represents a distinct improvement in satisfying consumer needs (Chandy \& Tellis 2017). Conversely, an incremental innovation is a product containing low levels of new knowledge (Dewar \& Dutton 1986). We selected these product typologies as the degree of product novelty may affect emotional reaction in consumers. Radical innovation, indeed, have been argued to generate stronger emotional reactions than incremental innovations, able to 
influence the evaluation of such products and affect adoption and diffusion process (Chaudhuri et al. 2010; Mandler 1982).

\section{Study 1}

The aim of study 1 was to test our conceptual model on a $2 \times 2$ design, by testing functional and hedonic products in both adoption and continuous usage scenarios. After individuating two stimuli products that differ in terms of their hedonic and functional nature, we conducted a survey research, distributed online, to investigate adoption and continuous usage decisions for both products.

\section{Design and procedure}

We selected the two products based on the results of a pre-test on four electronic devices. In the pretest 20 participants were asked "Would you characterise the [product] as primarily a functional product or an entertainment/enjoyable product?" with a 7-point scale, with 1 being "primarily for functional use" and 7 being "primarily for entertainment use", according to prior studies (Kempf, 1999). Based on the results of a paired t-test we selected a couple of products that presents a significant difference $(\mathrm{t} 19=3,418 ; \mathrm{p}<0.01)$ in terms of perceived functional versus hedonic characteristics: an $\mathrm{MP} 3$ player $(\mathrm{M}=5.4 ; \mathrm{SD}=1.39)$ and a fitness tracker $(\mathrm{M}=3.75$; $\mathrm{SD}=1.71)$. Further, both the MP3 player and the fitness tracker were common products, used by a large majority of the population, thus representing a credible consumption scenario.

Two surveys were conducted online, one about the functional product and one about the hedonic product. The surveys were developed using Survey Monkey tool (https://it.surveymonkey.com/). We distributed the questionnaires (i) through e-mail to a convenience sample (ii) through social media platforms (e.g. Facebook) and (iii) inside online forums to reach a variety of respondents. We posted the survey both on generalist social media platforms and online forums and in subject-specific forums (e.g. groups discussing sport, music, 
fitness, electronics). Further, we posted the surveys on both Italian and International social media, to enlarge the sample of respondents.

For each survey respondents were asked to report if they own a product in the category presented. Based on this response they were directed to the survey about the novel product (if they did not own it) or to the one about the familiar product (if they own it). In the survey on the novel product, a description and some pictures of the product were shown, in the other one respondents were inquired about the product they own. Questions were identical between the two conditions and the two products, with only slightly changes due to the rewording of the questions to a novel or a familiar product. Other questions, not related to the study, were proposed as well.

\section{Measurement and method of data analysis}

All constructs were adapted from prior literature. We measured attitude, anticipated positive emotions, anticipated negative emotions and value perceptions (purposive value, usability, monetary value, entertainment value, interpersonal interconnectivity, social enhancement, selfdiscovery) through self-reported scales. We measured intention to adopt/use as well, to confirm its relationship with attitude. Product nature has been measured to assess if it acts as a moderator between anticipated emotions and attitude. Value perceptions and intention were measured through seven-point Likert scale with the value 1 anchored to "strongly disagree" and 7 to "strongly agree". Anticipated emotions were assessed through 7-point items with alternatives ranging from 'not at all' to 'very much,' and with 'moderately' in the middle. Attitude was assessed through ten 7-point semantic differential items. Items for all constructs were listed in random order. Appendix A presents the measurement scales.

We used Partial Least Squares Structural Equation Modeling (PLS-SEM), a second-generation multivariate data analysis method that permits to test linear and additive models. We opted for 
PLS-SEM due to the explorative type of research (Hwang et al. 2010). We performed two path analyses, one for each condition (adoption and continuous usage). Our model was balanced in the weight of endogenous and exogenous constructs, meeting PLS-SEM's prediction goal (Hair et al. 2012). All our constructs were reflective.

\section{Preliminary analysis and common method variance}

We received 305 responses in the first half of 2015. After deletion of missing, incomplete and invalid responses, we obtained a valid dataset of 270 answers, of which 161 answers for novel products (people that did not own an MP3 player/fitness tracker) and 109 for familiar products (people who own an Mp3 player/fitness tracker). Demographic statistics are provided in Appendix B. A summary of descriptive statistics for each construct is provided in Appendix C. We checked that the two products (functional and hedonic) were not significantly different in their overall favorability. Indeed, the products analyzed should differ only in their perceived nature (functional versus hedonic) in order to provide clear indications on the process elicited by each product. Other differences between the products could affect PAE and NAE in not controllable ways. To check for this possibility, a t-test of the difference between attitudes for the two products was performed. Means were not significantly different $(\mathrm{t}(268)=1.15, \mathrm{p}=0.25)$, thus confirming this is not an issue in the study.

To assure that common method variance will not affect our results we developed the survey using different scales types (Likert-scale; semantic differential; multiple choices) and we randomised the order of items. Further, the complicated specifications in the regression model make it difficult for respondents to anticipate relationships in the framework or to use a cognitive map in answering. A posteriori, we examined the robustness of the results employing Harman's one-factor test, as suggested by Podsakoff, MacKenzie, Lee, \& Podsakoff (2003). Results show that the single factor was explaining less than $50 \%$ of the variance, thus we concluded that common method bias does not represent a significant threat to the study. 


\section{Results of Partial Least Square analysis (PLS-SEM)}

We examined the reliability and validity of constructs with the pooled data (Haenlein \& Kaplan 2004) through their composite reliability, AVE and AVE square root (Table 1). After checking for measure reliability we deleted one item from the entertainment value scale ("to play") and one from the attitude scale ("excited"). Further analyses were conducted on this data set.

\begin{tabular}{|c|c|c|c|c|c|c|c|c|c|c|c|c|c|}
\hline Construct & $\begin{array}{l}\text { Average } \\
\text { Variance } \\
\text { Extracted } \\
(\text { AVE) }\end{array}$ & $\begin{array}{l}\text { Composite } \\
\text { Reliability }\end{array}$ & AT & ENTER & SELF & INT & INTINT & NAE & PAE & USAB & MON & PURP & SOC \\
\hline AT & 0.69 & 0.96 & $\mathbf{0 . 8 3}^{\mathrm{a}}$ & & & & & & & & & & \\
\hline ENTER & 0.79 & 0.92 & 0.31 & 0.89 & & & & & & & & & \\
\hline SELF & 0.89 & 0.94 & 0.24 & -0.13 & 0.94 & & & & & & & & \\
\hline INT & 0.89 & 0.96 & 0.63 & 0.44 & 0.16 & 0.95 & & & & & & & \\
\hline INTINT & 0.91 & 0.95 & 0.08 & 0.15 & 0.49 & 0.02 & 0.95 & & & & & & \\
\hline NAE & 0.75 & 0.96 & 0.38 & 0.20 & 0.04 & 0.29 & 0.06 & 0.87 & & & & & \\
\hline PAE & 0.86 & 0.97 & 0.67 & 0.38 & 0.30 & 0.62 & 0.19 & 0.46 & 0.93 & & & & \\
\hline USAB & 0.85 & 0.94 & 0.39 & 0.34 & 0.00 & 0.44 & -0.08 & 0.20 & 0.38 & 0.92 & & & \\
\hline MON & 0.95 & 0.97 & 0.30 & 0.18 & 0.06 & 0.36 & 0.01 & 0.25 & 0.36 & 0.38 & 0.97 & & \\
\hline PURP & 0.79 & 0.92 & 0.57 & 0.26 & 0.32 & 0.67 & 0.21 & 0.35 & 0.62 & 0.38 & 0.44 & 0.89 & \\
\hline SOC & 0.95 & 0.97 & 0.14 & 0.16 & 0.39 & 0.00 & 0.52 & 0.20 & 0.29 & -0.06 & 0.07 & 0.10 & 0.97 \\
\hline \multicolumn{14}{|l|}{$\mathbf{N}=\mathbf{2 7 0}$} \\
\hline \multicolumn{14}{|c|}{$\begin{array}{l}{ }^{\text {a }} \text { Square root of } \boldsymbol{A V E} \\
\text { AT (attitude); ENTER (entertainment value); SELF (self-discovery); INT (Intention); INTINT (interpersonal interconnectivity); NAE } \\
\text { (negative anticipated emotions); PAE (positive anticipated emotions); USAB (usability); MON (monetary value); PURP (purposive value); } \\
\text { SOC (social-enhancement) }\end{array}$} \\
\hline \multicolumn{14}{|c|}{ We used the split dataset for PLS multigroup comparisons to analyse adoption versus } \\
\hline \multicolumn{14}{|c|}{ continuous usage (Sarstedt et al. 2011). Our sample size $(n=161$ for adoption and $n=109$ for } \\
\hline \multicolumn{14}{|c|}{ continuous usage) was adequate, being more than ten times the largest number of structural } \\
\hline \multicolumn{14}{|c|}{ paths directed to a particular latent construct in the structural model (Barclay et al. 1995). } \\
\hline \multicolumn{14}{|c|}{ Results are shown below (Figure 2 and Figure 3), where grey boxes represent significant } \\
\hline
\end{tabular}


Figure 2 Study 1 results - adoption

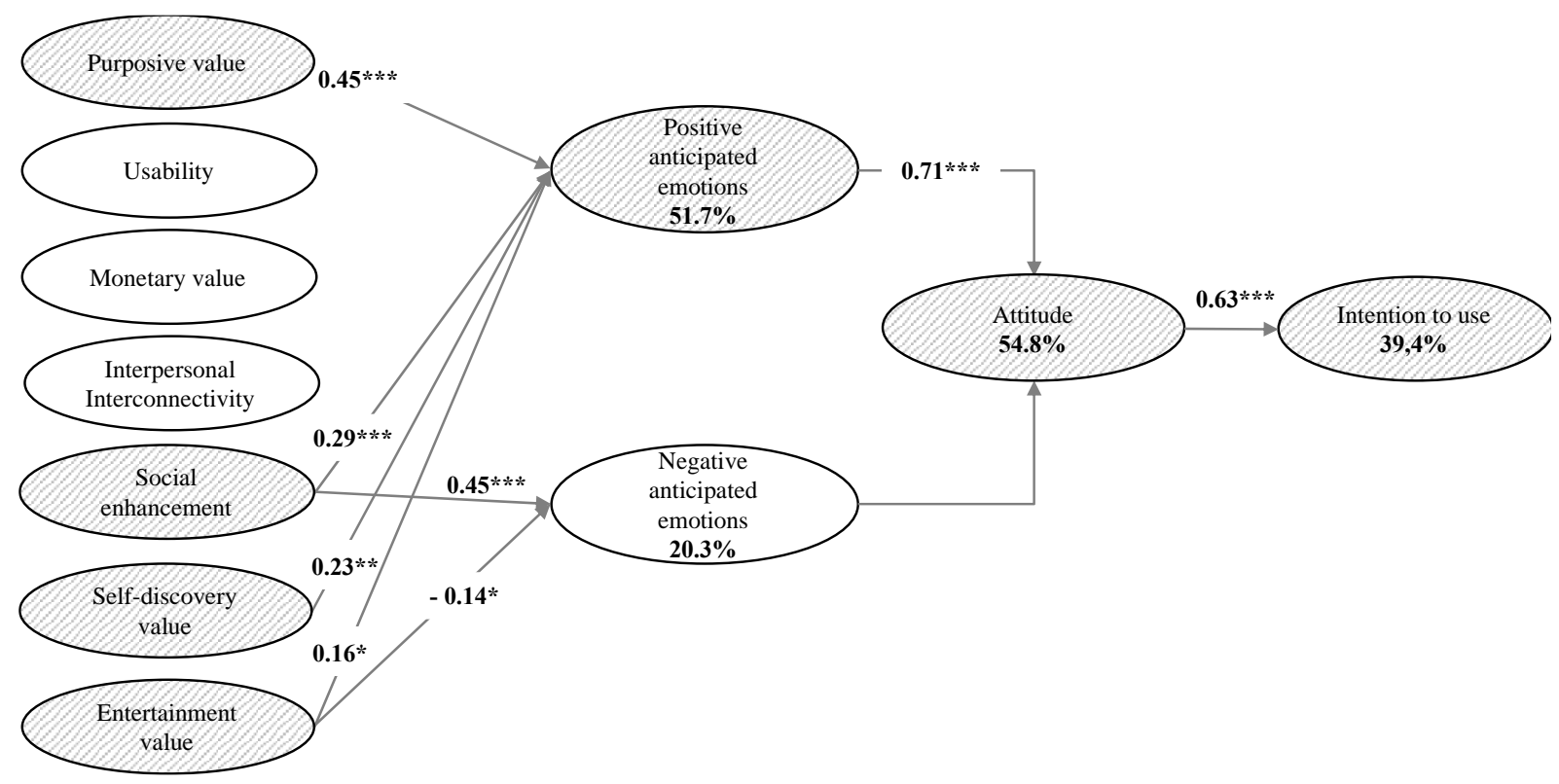

Figure 3 Study 1 results - continuous usage

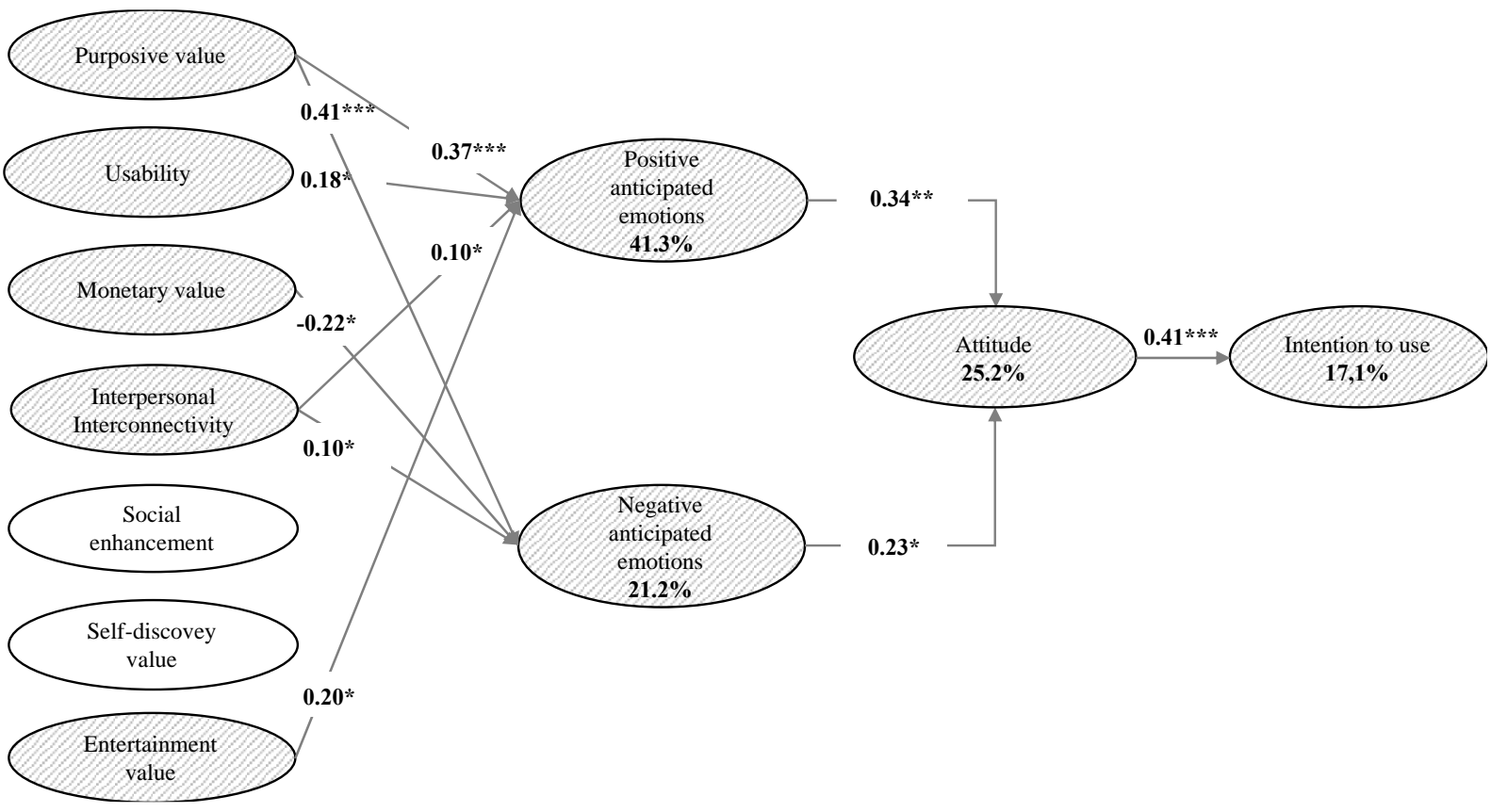

For each significant relationship a group comparison through t-test was performed, to check if such relationship was statistically different in the two conditions. Detailed results are provided in Appendix D. For each condition, we run 5000 bootstrap samples as suggested by Hair et al. (2011). The number of iterations to find convergence were respectively 4 and 5 , suggesting the 
goodness of the model. Model's predictive relevance has been assessed through StoneGeisser'values (Stone 1974; Geisser 1974) using blindfolding procedures (Tenenhaus \& Vinzi 2005). Attitude, PAE, NAE and Intention showed values far above zero, thus confirming the predictive relevance of the constructs in the model. The inner model results suggest that PAE have the strongest effect on attitude both for adoption and continuous usage, confirming H1. NAE have a direct positive effect on attitude according to $\mathrm{H} 2$, but only for continuous usage. The effect of PAE and NAE on attitude was significantly different between adoption and continuous usage, confirming our H6. Attitude is confirmed as a predictor of intention (H3) in accordance with prior research (Davis 1989). Results showed that value perceptions influence PAE and NAE differently and that they strongly change between adoption and continuous usage, partially confirming our $\mathrm{H} 4, \mathrm{H} 5$ and $\mathrm{H} 7$. We verified the possibility that product nature operates as a moderator, interacting with predictors of decision-making as suggested by prior studies (e.g. Kempf 1999). Specifically, we tested if product nature was moderating the relationship between PAE and attitude, NAE and attitude and if it has a direct effect on attitude. We found no evidence of moderating effect on both PAE and NAE, neither a significant direct effect of product nature on attitude, for both adoption and continuous usage decisions. Table 2 summarizes results of the hypotheses testing.

\begin{tabular}{|c|c|c|}
\hline Hypothesis & Description & Result \\
\hline H1 & $\begin{array}{l}\text { Positive anticipated emotions, toward future product usage, } \\
\text { positively influence attitude }\end{array}$ & Accepted $^{\mathbf{1}}$ \\
\hline H2 & $\begin{array}{l}\text { Negative anticipated emotions, toward future product privation, } \\
\text { positively influence attitude }\end{array}$ & $\begin{array}{l}\text { Accepted }^{1} \text { for } \\
\text { continuous usage } \\
\text { Not accepted }{ }^{1} \text { for } \\
\text { adoption }\end{array}$ \\
\hline H3 & Attitude positively influences intention to use & Accepted $^{\mathbf{1}}$ \\
\hline H4 & $\begin{array}{l}\text { Value perceptions positively influence anticipated positive } \\
\text { emotions }\end{array}$ & Partially accepted ${ }^{12}$ \\
\hline H5 & $\begin{array}{l}\text { Value perceptions positively influence anticipated negative } \\
\text { emotions }\end{array}$ & Partially accepted $^{12}$ \\
\hline H6 & $\begin{array}{l}\text { The impact of anticipated emotions on attitude changes between } \\
\text { adoption and continuous usage }\end{array}$ & Accepted $^{\mathbf{1}}$ \\
\hline H7 & $\begin{array}{l}\text { The influence of value perceptions on anticipated emotions } \\
\text { changes between adoption and continuous usage }\end{array}$ & Partially accepted $^{12}$ \\
\hline
\end{tabular}




\section{Study 2}

The objective of Study 2 was to replicate Study 1, by testing our hypothesised relationships for both incremental and radical product innovations, in adoption and continuous usage scenarios. The empirical research followed two steps: (i) a pretest, in order to individuate two stimuli products that differ in terms of their perceived innovativeness, incremental versus radical; (ii) a survey research, conducted online, to investigate adoption and continuous usage decisions for both products.

\section{Design and procedure}

A team of researchers selected two products, a game console for the incremental innovation and a mobile virtual reality headset for the radical innovation. Such products should represent respectively an incremental and a radical innovation at the time in which the study has been conducted. To confirm this choice we conducted a pretest in which 26 subjects similar to those used in the final study evaluated the products. We employed the scale developed by Im et al. (2015) to measure the perceived innovativeness of the product, by using a 7-points Likert scale, with 1 being "strongly agree" and 7 being "strongly disagree". Specifically we introduced the question with "Compared with other competing products, this product..." followed by 6 items "is radically different", "can be considered as revolutionary", "is really out of the ordinary", "provides something not commonly found", "incorporates new ideas/concepts", "has unique features". We conducted a paired t-test that confirmed a significant difference (t25 $=5.61$; $\mathrm{p}<0.001)$ in the score of the game console $(\mathrm{M}=2.99 ; \mathrm{SD}=1.33)$ and the mobile virtual reality handset $(\mathrm{M}=5.31 ; \mathrm{SD}=1.23)$.

Following the pretest, two surveys, one about the incremental innovation and one about the radical innovation, were distributed online through Survey Monkey tool. We distributed the 
questionnaire through e-mail to a convenience sample and through social media platforms and online forums to reach a variety of respondents. The survey has been posted both on generalist online communities and social media and in subject-specific forums, to catch consumers actually using the products (e.g. forums discussing game consoles and personal electronic devices). The survey has been posted on both Italian and International platforms, to enlarge the sample of respondents. The remaining of the procedure is identical to the one of Study 1.

\section{Measurement and method of data analysis}

The measurement scales adopted are the ones used in Study 1, with wording adjustments according to the specific product typology. Data analysis has been performed through Partial Least Squares Structural Equation Modeling (PLS-SEM).

\section{Preliminary analysis and common method variance}

We collected 1.874 responses at the beginning of 2017. After deletion of missing, incomplete and invalid responses, we obtained a valid dataset of 1106 answers, of which 189 answers for adoption scenario and 917 for continuous usage scenario. Demographic statistics are provided in Appendix E. A summary of descriptive statistics for each construct is provided in Appendix F. We examined the robustness of the results against common method bias by employing Harman's one-factor test, as suggested by Podsakoff, MacKenzie, Lee, \& Podsakoff (2003). Results show that a single factor was explaining less than $50 \%$ of the variance, thus we concluded that common method bias does not represent a significant threat to the study.

\section{Results of Partial Least Square analysis (PLS-SEM)}

We performed two path analyses through PLS-SEM, one for each condition (adoption and continuous usage). Our sample size was adequate, being more than ten times the largest number of structural paths directed to a particular latent construct in the structural model (Barclay et al. 
1995). We examined the reliability and validity of constructs with the pooled data (Haenlein \& Kaplan 2004) through their composite reliability, AVE and AVE square root (Table 3).

Table 3. Study 2 - Inter construct correlation and reliability measures

\begin{tabular}{|c|c|c|c|c|c|c|c|c|c|c|c|c|c|}
\hline $\begin{array}{l}\text { Construc } \\
\text { t }\end{array}$ & $\begin{array}{l}\text { Average } \\
\text { Variance } \\
\text { Extracted } \\
\text { (AVE) }\end{array}$ & $\begin{array}{l}\text { Composite } \\
\text { Reliability }\end{array}$ & AT & ENTER & SELF & INT & $\begin{array}{c}\text { INTIN } \\
\mathrm{T}\end{array}$ & NAE & PAE & USAB & MON & PURP & SOC \\
\hline AT & 0.66 & 0.95 & $0.81^{\mathrm{a}}$ & & & & & & & & & & \\
\hline ENTER & 0.67 & 0.89 & 0.53 & 0.82 & & & & & & & & & \\
\hline SELF & 0.89 & 0.94 & 0.34 & 0.15 & 0.94 & & & & & & & & \\
\hline INT & 0.92 & 0.97 & 0.67 & 0.60 & 0.22 & 0.96 & & & & & & & \\
\hline INTINT & 0.88 & 0.93 & 0.28 & 0.34 & 0.43 & 0.25 & 0.94 & & & & & & \\
\hline NAE & 0.64 & 0.94 & 0.51 & 0.35 & 0.26 & 0.45 & 0.24 & 0.80 & & & & & \\
\hline PAE & 0.80 & 0.96 & 0.73 & 0.54 & 0.37 & 0.67 & 0.30 & 0.53 & 0.89 & & & & \\
\hline USAB & 0.76 & 0.90 & 0.47 & 0.47 & 0.17 & 0.49 & 0.21 & 0.28 & 0.46 & 0.87 & & & \\
\hline MON & 0.92 & 0.96 & 0.50 & 0.41 & 0.25 & 0.51 & 0.21 & 0.34 & 0.51 & 0.45 & 0.96 & & \\
\hline PURP & 0.78 & 0.91 & 0.63 & 0.44 & 0.45 & 0.55 & 0.41 & 0.51 & 0.62 & 0.43 & 0.47 & 0.88 & \\
\hline SOC & 0.87 & 0.93 & 0.17 & 0.10 & 0.43 & 0.13 & 0.22 & 0.22 & 0.23 & 0.08 & 0.14 & 0.20 & 0.94 \\
\hline $\begin{array}{l}\mathrm{N}=1106 \\
{ }^{a} \text { Square }\end{array}$ & $A V E$ & & & & & & & & & & & & \\
\hline
\end{tabular}

We used the split dataset for PLS multigroup comparisons to analyse adoption versus continuous usage (Sarstedt et al. 2011). Results are shown below (Figure 4 and Figure 5), where grey boxes represent significant relationships (complete results are provided in Appendix G). 
Figure 4 Study 2 results - adoption

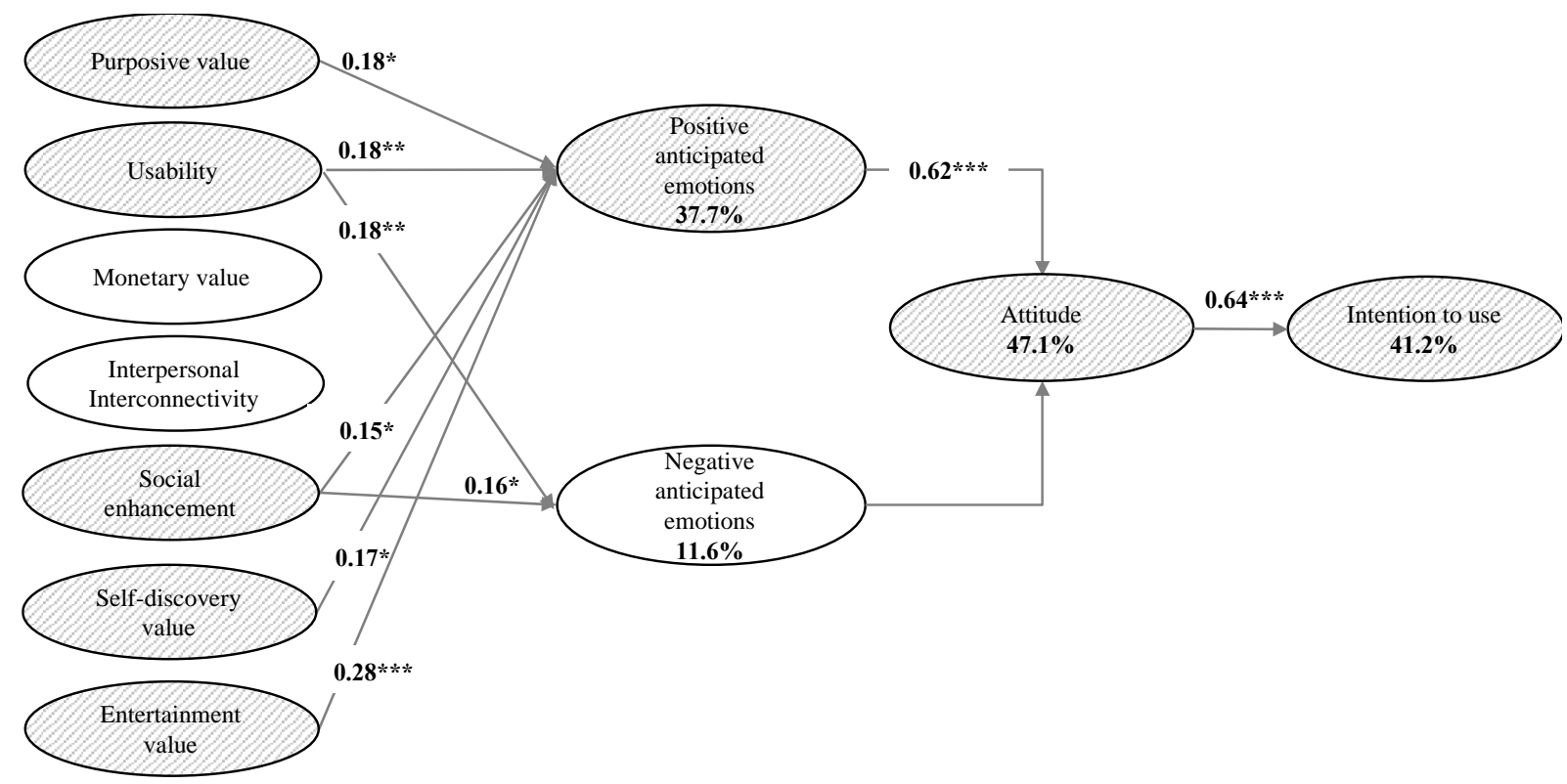

Figure 5 Study 2 results - continuous usage

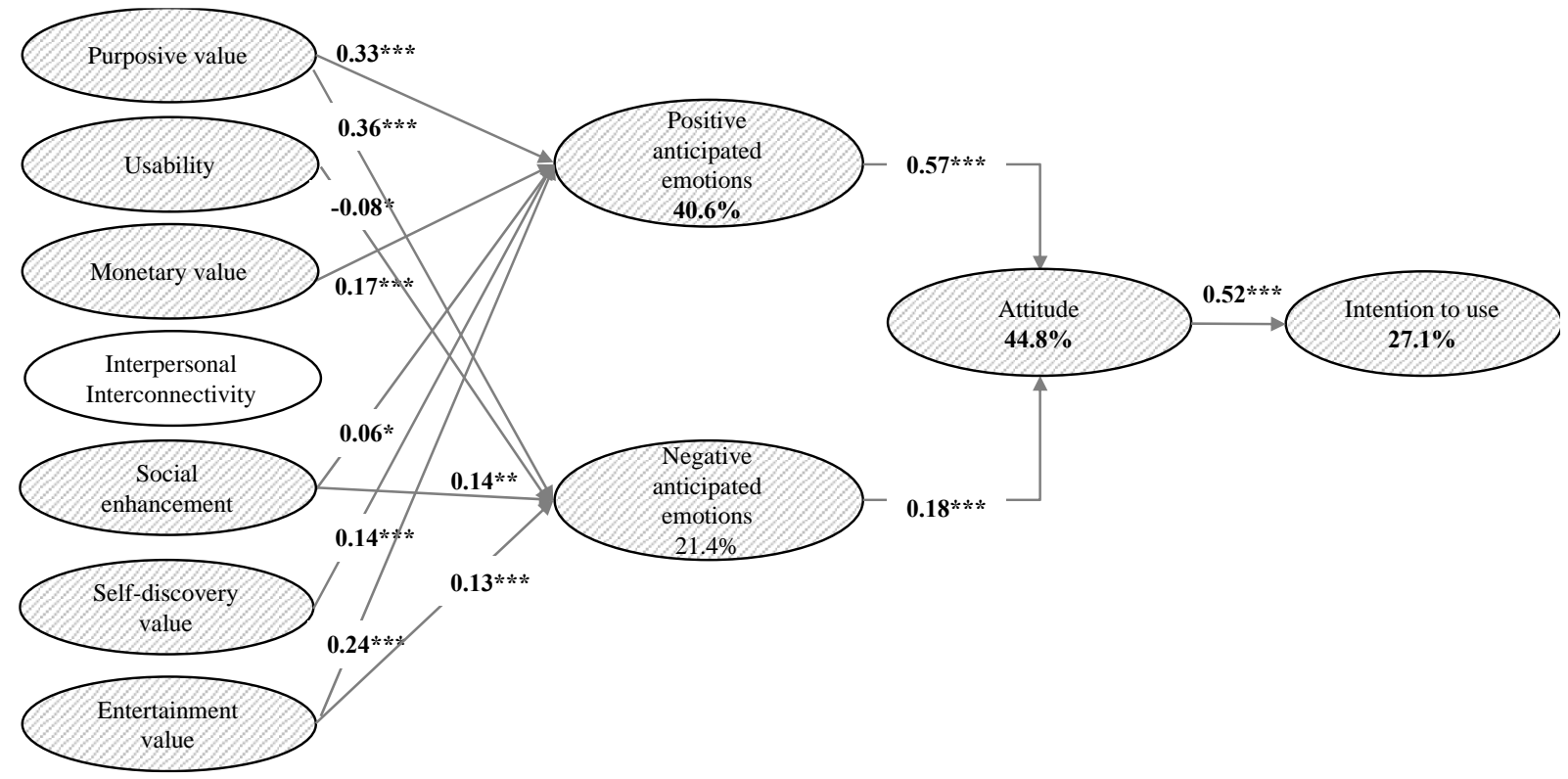

For each significant relationship a group comparison through t-test was performed, to check if such relationship was statistically different in the two conditions. For each model, we run 5000 bootstrap samples as suggested by Hair et al. (2011). Model's predictive relevance has been assessed through Stone-Geisser'values (Stone 1974; Geisser 1974) using blindfolding procedures (Tenenhaus \& Vinzi 2005). Attitude, PAE, NAE and Intention showed values far above zero, thus confirming the predictive relevance of the constructs. 
Consistent with H1, PAE have the strongest effect on attitude both for adoption and continuous usage. NAE do not influence attitude in the adoption scenario, but have a positive impact on the continuous usage scenario, confirming findings of Study 1. We found different effect of NAE between adoption and continuous usage, but not of PAE, only partially confirming H6. Attitude is confirmed as a predictor of intention (H3). Results showed that value perceptions influence PAE and NAE differently and that they strongly change between adoption and continuous usage, according to $\mathrm{H} 4, \mathrm{H} 5$ and $\mathrm{H} 7$. We verified the possibility that product innovativeness, radical versus incremental, operates as a moderator, interacting with predictors of decision-making. We found no evidence of moderating effect on both PAE and NAE, neither a significant direct effect of product nature on attitude, for both adoption and continuous usage decisions. Table 4 summarizes the results of hypotheses testing.

Table 4. Study 2 - Summary of hypotheses testing

\begin{tabular}{|c|c|c|}
\hline Hypothesis & Description & Result \\
\hline H1 & $\begin{array}{l}\text { Positive anticipated emotions, toward future product usage, } \\
\text { positively influence attitude }\end{array}$ & Accepted $^{\mathbf{1}}$ \\
\hline H2 & $\begin{array}{l}\text { Negative anticipated emotions, toward future product privation, } \\
\text { positively influence attitude }\end{array}$ & $\begin{array}{l}\text { Accepted }^{1} \text { for } \\
\text { continuous usage } \\
\text { Not accepted }^{1} \text { for } \\
\text { adoption }\end{array}$ \\
\hline H3 & Attitude positively influences intention to use & Accepted ${ }^{1}$ \\
\hline H4 & $\begin{array}{l}\text { Value perceptions positively influence anticipated positive } \\
\text { emotions }\end{array}$ & Partially accepted ${ }^{12}$ \\
\hline H5 & $\begin{array}{l}\text { Value perceptions positively influence anticipated negative } \\
\text { emotions }\end{array}$ & Partially Accepted ${ }^{\mathbf{1 2}}$ \\
\hline H6 & $\begin{array}{l}\text { The impact of anticipated emotions on attitude changes between } \\
\text { adoption and continuous usage }\end{array}$ & $\begin{array}{l}\text { Accepted }^{1} \text { for NAE } \\
\text { Not accepted }{ }^{\mathbf{1}} \text { for PAE }\end{array}$ \\
\hline H7 & $\begin{array}{l}\text { The influence of value perceptions on anticipated emotions } \\
\text { changes between adoption and continuous usage }\end{array}$ & Partially accepted ${ }^{12}$ \\
\hline \multicolumn{3}{|c|}{${ }^{1}$ at the 0.05 level of Alpha or lower } \\
\hline 2 only a set & alue perceptions is activated & \\
\hline
\end{tabular}

\section{Discussion}

This research confirms that anticipated emotions strongly influence attitude. Further, they differ between adoption and continuous usage. In particular, findings show that PAE are a strong driver of attitude, particularly in adoption decisions. This is true for both hedonic and functional 
products (Study 1) and incremental and radical product innovations (Study 2). Thus, PAE work as a motivational factor for novel products while, after the product has become part of the consumer daily life and routine, their motivational effect decrease. NAE, conversely, are a significant predictor of attitude toward continuous usage only, a result confirmed in all our scenarios (hedonic and functional products and incremental and radical product innovations). Long term usage mirrors the product meaningfulness in the consumer life, hence a usage constraint generates negative feelings in the consumer. Conversely, for new products, the lack of prior experience makes NAE irrelevant.

Further, our findings confirm that value perceptions differ in their impact on PAE and NAE according to the underlying decision-making process (adoption or continuous usage). Monetary value and interpersonal interconnectivity are irrelevant drivers in adoption decisions, while they become significant drivers in continuous usage decisions in all our scenarios (with the exception of interpersonal interconnectivity in Study 2). The importance of interpersonal interconnectivity mirrors the willingness to keep the social connections generated thanks to the product usage. The influence of monetary value, being negative on NAE in Study 1 and positive on PAE in Study 2 may suggest that sunk-costs psychologically stimulate use to avoid the perception of money loss coupled with the positive emotions generated by a good value for money. Purposive value and entertainment value are the only two perceptions that significantly influence both adoption and continuous usage decisions for all product typologies. Purposive value shows to be relevant in long-term experiences with products, thanks to functional dependency and familiarity, which increase the utility value for the user. Entertainment value positively influences emotions in continuous usage as well, in contrast with prior research that found hedonic aspects to lose relevance over time (Karapanos et al. 2009; Wilamowitz-Moellendorff et al. 2006). Consumers seem to value the entertainment potential of a product even after adoption. Social enhancement and self-discovery values have a greater impact on product 
adoption decisions, decreasing or disappearing while evaluating continuous usage. Selfdiscovery value plays an important role in adoption, thanks to the possibility of learning new knowledge, but the vanishing of novelty over time makes this value less relevant in further usage decisions. Social enhancement derived from brand image and status perception is relevant in adoption decisions but once consumers own the product this factor loses relevance. The blurred results for product usability, holding different effects across scenarios, need further research.

Our findings show that product nature does not affect anticipated emotions, in both Study 1 and Study 2. Thus, both functional and hedonic products and incremental and radical innovations seem to be evaluated on emotional bases. These results are in contrast with prior research suggesting that functional and hedonic products should be treated differently as arise different emotional responses (e.g. Kempf, 1999). Thus, functional product evaluation does not seem only cognitive oriented, but influenced by affective responses in the same extend as hedonic products. Our results suggest that consumers evaluate the future experience they may have with a functional product in terms of feelings it is able to generate. Further, prior research advocates that radical innovations generate stronger emotional reactions than incremental innovations, and such emotions influence the product evaluation, adoption and diffusion process (Chaudhuri et al. 2010; Mandler 1982). Our findings, however, indicate that radical and incremental product innovations do not differ in the anticipated emotions they elicit in consumers: incremental innovations elicit emotions despite they have a inherently lower level of new knowledge compared to radical innovations.

\section{Implications for research}

Product decision-making research has not explored the role of anticipated emotions on product adoption and usage to date. Our research contributes to theory building in this area. We propose a new conceptual model that views product value perceptions as drivers of anticipated emotions, 
in their turn influencing attitude toward a product. Across two empirical studies, conducted on consumer samples, we found support for our assumptions. The first contribution of this work is to the body of research on product decision-making, where we extend product adoption and usage theory by depicting and empirically validating a different pattern through which consumers move in their decisions about product usage. In this way, we enrich extant research by providing evidence of anticipated emotions influence on the continued use of products that have already been adopted, in addition to those being considered for adoption. Further, we contribute to academic research by presenting evidence of the effect of value perceptions, namely purposive value, usability, monetary value, self-discovery value, social enhancement, interpersonal interconnectivity and entertainment value on anticipated emotions and showing how value perceptions change in importance between adoption and continuous usage. We confirm that anticipated emotions, being dynamic responses, are contingent to the product evaluation process, thus depend on value perceptions. Finally, our results raise doubts on the different influence on decision-making generated by functional and hedonic products (e.g. Kempf and Smith, 1998; Kempf, 1999) and by incremental and radical innovations (e.g. Chaudhuri et al., 2010; Mandler, 1982). We did not find, indeed, any moderating effect of the product nature on emotional and cognitive responses.

\section{Managerial implications}

How do marketing efforts aimed at building emotional connections with the brand affect consumer choices? Our results suggest that emotions affect consumer choices differently in adoption versus continuous usage decisions. During a new product launch, marketers should concentrate their effort on the creation of positive anticipated emotions in new customers by leveraging the ability of the product to increase consumer well-being thanks to its learning opportunity, entertainment features and social image. While communicating with existing customers, above the creation of positive anticipated emotions, marketers need to focus on the 
leveraging of negative emotional consequences associated with a potential switch to competitor products, by highlighting the benefits consumer may lose.

Such emotional responses can be enhanced by working on the product value perceptions. To increase functionality perception marketers may work on the provision of comprehensive product applications or complementary services and tools. Further, constant upgrades of the system and new contents and functionalities are needed to keep the purposive value of the product along time and prevent brand switch. In a similar vein, constantly updates and new hedonic content may help in keeping the product entertainment potential over time. Highlighting the learning opportunities of new products and investing in the creation of a distinctive brand image can be effective strategies during new products launch. Conversely, to incentivize continuous usage, marketers should try to keep customers interest over time by facilitating networks of relationships among them. Tools improving user community matching, such as the possibility to create profile pages, save preferences and share consumption history may be useful to this extent. Brand virtual communities, blogs, fan groups or events for the community members are other desirable instruments. If customers feel part of a community, they may use the product more and for a longer time as, above its mere functionalities, it enables users to keep connected.

\section{Limitations and future research}

A limitation of our work derives from the use of cross-sectional surveys. Despite we used measures already validated in literature and our samples were adequate for the analysis, future research may use an experimental design to investigate more in depth the individual relationships we proposed. Further, additional research is needed to investigate the influence of value perceptions on anticipated emotions in different contexts, to further validate our findings and provide an answer to open issues, such as the effect of product usability on emotions. A third limit derives from the specific classification we used to assess anticipated emotions. 
Despite we investigated distinct emotional reactions (e.g. delight, happiness, anxiety, sadness etc), we further discussed them in terms of valence (positive versus negative anticipated emotions) but not in terms of arousal. Thus, future research may adopt different multidimensional classifications or even focus on discrete emotions, identified as individual and basic entities such as happiness, surprise and disgust, to depict the affective process leading to decision-making. Finally, this research is the first attempt to examine the effect of anticipated emotions in product decision-making. Thus, there is room for further research to understand how anticipated emotional responses drive cognitive processes in product decision-making.

\section{References}

Bagozzi, R. \& Baumgartner, H., 2000. The role of emotions in goal-directed behavior. In The why of consumption: Contemporary perspectives on consumer motives, goals, and desires. pp. 36-58.

Bagozzi, R.P., Dholakia, U.M. \& Basuroy, S., 2003. How Effortful Decisions Get Enacted: The Motivating Role of Decision Processes, Desires, and Anticipated Emotions. Journal of Behavioral Decision Making, 16(4), pp.273-295.

Bagozzi, R.P. \& Lee, K.-H., 1999. Consumer Resistance To, and Acceptance Of, Innovations. NA - Advances in Consumer Research, 26, pp.218-225.

Bagozzi, R.P., Wong, N. \& Yi, Y., 1999. The role of culture and gender in the relationship between positive and negative affect. Cognition \& Emotion, 13(6), pp.641-672.

Barclay, D., Higgins, C. \& Thompson, R., 1995. The Partial Least Squares (PLS) Approach to Causal Modelling: Personal Computer Adoption and Use as an Illustration. Technology Studies, 2(2), pp.285-309.

Batra, R. \& Ahtola, O., 1991. Measuring the hedonic and utilitarian sources of consumer attitudes. Marketing letters, 2(2), pp.159-170.

Batra, R. \& Stayman, D., 1990. The role of mood in advertising effectiveness. Journal of Consumer research, pp.203-214.

Chandy, R. \& Tellis, G., 2017. Organizing for radical product innovation: The overlooked role of willingness to cannibalize. Journal of marketing research, 35(4), pp.474-487.

Chaudhuri, A., Aboulnasr, K. \& Ligas, M., 2010. Emotional Responses on Initial Exposure to a Hedonic or Utilitarian Description of a Radical Innovation. Journal of Marketing Theory and Practice, 18(4), pp.339-359. 
Coary, S. \& Poor, M., 2016. How consumer-generated images shape important consumption outcomes in the food domain. Journal of Consumer Marketing, 33(1), pp.1-8.

Coricelli, G., Dolan, R. \& Sirigu, A., 2007. Brain, emotion and decision making: the paradigmatic example of regret. Trends in cognitive sciences, 11(6), pp.258-265.

Davis, F., 1989. Perceived usefulness, perceived ease of use, and user acceptance of information technology. MIS quarterly, 13(3), pp.319-340.

Desmet, P. \& Hekkert, P., 2007. Framework of Product Experience. , 1(1), pp.57-66.

Dewar, R.D. \& Dutton, J.E., 1986. The Adoption of Radical and Incremental Innovations: An Empirical Analysis. Management Science, 32(11), pp.1422-1433.

Dholakia, U., Bagozzi, R. \& Pearo, L., 2004. A social influence model of consumer participation in network-and small-group-based virtual communities. International Journal of Research in Marketing, 21(3), pp.241-263.

Elgaaied, L., 2012. Exploring the role of anticipated guilt on pro-environmental behavior-A suggested typology of residents in France based on their recycling patterns. Journal of Consumer Marketing, 29(5), pp.369-377.

Fishbein, M. \& Ajzen, I., 1975. Belief, attitude, intention, and behavior: an introduction to theory and research, Addison-Wesley Publishing Company.

Flanagin, A. \& Metzger, M., 2001. Internet use in the contemporary media environment. Human communication research, 27(1), pp.153-181.

Frijda, N.H., 1986. The emotions, Cambridge Univeristy Press.

Geisser, S., 1974. A predictive approach to the random effect model. Biometrika, 61(1), pp.101-107.

Gillison, S., Reynolds, K. \& Biswas, D., 2016. Shopping for yourself versus shopping for someone else. Journal of Consumer Marketing, 33(4), pp.225-234.

Gleicher, F. \& Boninger, D., 1995. With an eye toward the future: The impact of counterfactual thinking on affect, attitudes, and behavior. In What might have been: The social psychology of counterfactual thinking. pp. 283-304.

Haenlein, M. \& Kaplan, A., 2004. A beginner's guide to partial least squares analysis. Understanding statistics, 3(4), pp.283-297.

Hair, J. et al., 2012. An assessment of the use of partial least squares structural equation modeling in marketing research. Journal of the Academy of Marketing Science, 40(3), pp.413-433.

Hair, J., Ringle, C. \& Sarstedt, M., 2011. PLS-SEM: Indeed a silver bullet. Journal of Marketing Theory and Practice, 19(2), pp.139-152. 
Holbrook, M. \& Batra, R., 1987. Assessing the role of emotions as mediators of consumer responses to advertising. Journal of consumer research, pp.404-420.

Holbrook, M.B. \& Hirschman, E.C., 1982. The experiential aspects of consumption: Consumer fantasies, feelings, and fun. Journal of Consumer Research, 9(2), pp.132-140.

Hwang, H. et al., 2010. A comparative study on parameter recovery of three approaches to structural equation modeling. Journal of Marketing Research, 47(4), pp.699-712.

Im, S., Bhat, S. \& Lee, Y., 2015. Consumer perceptions of product creativity, coolness, value and attitude. Journal of Business Research, 68(1), pp.166-172.

Jordan, P., 2002. Designing pleasurable products: An introduction to the new human factors, CRC Press.

Karahanna, E., Straub, D. \& Chervany, N., 1999. Information technology adoption across time: A cross-sectional comparison of pre-adoption and post-adoption beliefs. MIS quarterly, 23(2), pp.183-213.

Karapanos, E., 2013. User experience over time. In Modeling Users' Experiences with Interactive Systems. Springer Berlin Heidelberg, pp. 57-83.

Karapanos, E. et al., 2009. User experience over time: An initial framework. Proceedings of the 27th SIGCHI Conference on Human Factors in Computing Systems, pp.729-738.

Kempf, D., 1999. Attitude formation from product trial: Distinct roles of cognition and affect for hedonic and functional products. Psychology \& Marketing, 16(1), pp.35-50.

Kempf, D. \& Smith, R., 1998. Consumer processing of product trial and the influence of prior advertising: A structural modeling approach. Journal of Marketing Research, 35(3), pp.325-338.

Krishna, A., 2012. An integrative review of sensory marketing: Engaging the senses to affect perception, judgment and behavior. Journal of Consumer Psychology, 22(3), pp.332-351.

Kujala, S. et al., 2011. UX Curve: A method for evaluating long-term user experience. Interacting with Computers, 23(5), pp.473-483.

Lazarus, R., 1991. Cognition and motivation in emotion. American psychologist, 46(4), pp.352367.

Mandler, G., 1982. The structure of value: accounting for taste. In Affect and Cognition: The 17th Annual Carnegie Symposium. pp. 3-36.

Mendoza, V. \& Novick, D., 2005. Usability over time. In ACM, ed. Proceedings of the 23rd annual international conference on Design of communication: documenting \& designing for pervasive information. pp. 151-158. 
Mora, P. \& Moscarola, J., 2010. Representations of the emotions associated with a wine purchasing or consumption experience. International Journal of Consumer Studies, 34(6), pp.674-683.

Norman, D., 2004. Emotional design: Why we love (or hate) everyday things, Basic Books.

Overby, J.W. \& Lee, E.-J., 2006. The effects of utilitarian and hedonic online shopping value on consumer preference and intentions. Journal of Business Research, 59(10-11), pp.1160-1166.

Perugini, M. \& Bagozzi, R., 2001. The role of desires and anticipated emotions in goal-directed behaviours: Broadening and deepening the theory of planned behaviour. British Journal of Social Psychology, 40(1), pp.79-98.

Phillips, D. \& Baumgartner, H., 2002. The role of consumption emotions in the satisfaction response. Journal of Consumer Psychology, 12(3), pp.243-252.

Plassmann, H. \& O’Doherty, J., 2008. Marketing actions can modulate neural representations of experienced pleasantness. Proceedings of the National Academy of Sciences, 105(3), pp.1050-1054.

Podsakoff, P. et al., 2003. Common method biases in behavioral research: a critical review of the literature and recommended remedies. Journal of applied Psychology, 88(5), p.879.

Pontiggia, A. \& Virili, F., 2010. Network effects in technology acceptance: Laboratory experimental evidence. International Journal of Information Management, 30(1), pp.6877.

Sarstedt, M., Henseler, J. \& Ringle, C., 2011. Multigroup analysis in partial least squares (PLS) path modeling: Alternative methods and empirical results. Advances in International Marketing, 22(1), pp.195-218.

Sheth, J.N., 1981. Psychology of Innovation Resistance: The Less Developed Concept (LDC) in Diffusion Research. Research in Marketing, 4, pp.273-282.

Stone, M., 1974. Cross-validatory choice and assessment of statistical predictions. Journal of the Royal Statistical Society. Series B (Methodological), 36(2), pp.111-147.

Tenenhaus, M. \& Vinzi, V., 2005. PLS path modeling. Computational statistics \& analysis, 48(1), pp.159-205.

Vaughan, G. \& Hogg, M., 2005. Introduction to social psychology, Pearson Education Australia. Available at: http://espace.library.uq.edu.au/view/UQ:40925 [Accessed October 7, 2015].

Wilamowitz-Moellendorff, M. von, Hassenzahl, M. \& Platz, A., 2006. Dynamics of user experience: How the perceived quality of mobile phones changes over time. In User Experience - Towards a unified view, Workshop at the 4th Nordic Conference on HumanComputer Interaction, pp. 74-78. 
Wu, M.-C. \& Kuo, F.-Y., 2008. An empirical investigation of habitual usage and past usage on technology acceptance evaluations and continuance intention. ACM SIGMIS Database, 39(4), p.48.

Yogasara, T. \& Popovic, V., 2011. General characteristics of anticipated user experience (AUX) with interactive products. In $n$ Proceedings of IASDR2011: the 4th World Conference on Design Research: Diversity and Unity. pp. 1-11.

Zeelenberg, M. et al., 2000. On bad decisions and disconfirmed expectancies: The psychology of regret and disappointment. Cognition \& Emotion, 14(4), pp.521-541.

\section{Appendix A. Measurement scales}

\begin{tabular}{|c|c|}
\hline Construct & Measures \\
\hline $\begin{array}{l}\text { Self-discovery } \\
\text { Flanagin \& Metzger (2001) }\end{array}$ & $\begin{array}{l}\text { I use the [product] } \\
\text { To learn about myself and others that use it } \\
\text { To gain insight into myself }\end{array}$ \\
\hline $\begin{array}{l}\text { Interpersonal } \\
\text { interconnectivity } \\
\text { Flanagin \& Metzger (2001) }\end{array}$ & $\begin{array}{l}\text { I use the [product] } \\
\text { To have something to do with others that use it } \\
\text { To stay in touch with others that use it }\end{array}$ \\
\hline $\begin{array}{l}\text { Social enhancement } \\
\text { Flanagin \& Metzger (2001) }\end{array}$ & $\begin{array}{l}\text { I use the [product] } \\
\text { To impress } \\
\text { To feel important }\end{array}$ \\
\hline $\begin{array}{l}\text { Entertainment value } \\
\text { Flanagin \& Metzger (2001) }\end{array}$ & $\begin{array}{l}\text { I use the [product] } \\
\text { To be entertained } \\
\text { To play } \\
\text { To relax } \\
\text { To pass the time away when bored }\end{array}$ \\
\hline $\begin{array}{l}\text { Purposive value } \\
\text { Davis (1989) }\end{array}$ & $\begin{array}{l}\text { I find the [product] to be useful in my daily life } \\
\text { Using the [product] increases my chances of achieving things } \\
\text { that are important to me } \\
\text { Overall, I find the [product] to be useful }\end{array}$ \\
\hline $\begin{array}{l}\text { Usability } \\
\text { Davis (1989) }\end{array}$ & $\begin{array}{l}\text { I find my interaction with the [product] clear and understandable } \\
\text { It is easy to become skillful at using the [product] } \\
\text { I find the [product] to be easy to use }\end{array}$ \\
\hline $\begin{array}{l}\text { Monetary value } \\
\text { Sweeney \& Soutar (2001) }\end{array}$ & $\begin{array}{l}\text { The [product] } \\
\text { Offer a good value for money } \\
\text { Is a good product for the price }\end{array}$ \\
\hline
\end{tabular}




\begin{tabular}{ll} 
Positive anticipated & If I can use the [product] in the next 6 months I will feel \\
emotions & Excited \\
Bagozzi and Pieters (1998) & Delighted \\
& Happy \\
& Glad \\
& Satisfied \\
& Content \\
& If I cannot use the [product] in the next 6 months I will feel \\
& Angry \\
emotions & Frustrated \\
Bagozzi and Pieters (1998) & Nervous \\
& Agitated \\
& Sad \\
& Disappointed \\
& Depressed \\
& Uncomfortable \\
& Anxious \\
& For me personally, adopting this product in the next six months \\
& can be described as \\
& Enjoyable-unenjoyable \\
& Pleasant-unpleasant \\
Comfortable-uncomfortable & Attractive-unattractive \\
Appealing-unappealing \\
Rewarding-punishing \\
Wise-foolish \\
Beneficial-harmful \\
Useful-useless \\
Good-bad \\
\hline I intend to use the [product] in the future \\
I predict that I would use the [product] in the future \\
I plan to use the [product] \\
\hline
\end{tabular}

\section{Appendix B. Demographic statistics (Study 1)}

\begin{tabular}{llll}
\hline Gender & \multicolumn{3}{l}{ Nationality } \\
\hline Male & $55.9 \%$ & Italy & $71 \%$ \\
Female & $44.1 \%$ & Other Countries & $29 \%$ \\
\hline Age & & Education \\
\hline $18-27$ & $63.7 \%$ & High School/College & $39.6 \%$ \\
$28-35$ & $13 \%$ & 3-year Bachelor D. & $26.3 \%$ \\
$36-45$ & $8.1 \%$ & 5-year Master D. & $25.2 \%$ \\
$46-60$ & $11.5 \%$ & Degree (JD, MD) & $5.6 \%$ \\
61 or over & $3.7 \%$ & Other & $3.3 \%$ \\
$\mathbf{N = 2 7 0}$ & & & \\
\hline
\end{tabular}


Appendix C. Descriptive statistics (Study 1)

\begin{tabular}{lcccccccc}
\hline \multirow{2}{*}{ Construct } & \multicolumn{3}{c}{ Adoption } & \multicolumn{3}{c}{ Continuous usage } \\
\cline { 2 - 9 } & \multicolumn{2}{c}{ Functional } & \multicolumn{2}{c}{ Hedonic } & \multicolumn{2}{c}{ Functional } & \multicolumn{2}{c}{ Hedonic } \\
\cline { 2 - 9 } PURP & Mean & SD & Mean & SD & Mean & SD & Mean & SD \\
\hline USAB & 5.06 & 1.44 & 3.73 & 1.50 & 5.33 & 1.29 & 4.75 & 1.27 \\
\hline MON & 3.12 & 0.98 & 5.52 & 1.16 & 5.65 & 1.36 & 6.08 & 0.85 \\
\hline SELF & 3.84 & 1.30 & 3.25 & 1.41 & 5.06 & 1.87 & 5.08 & 1.31 \\
\hline INTINT & 2.45 & 1.34 & 2.84 & 1.51 & 2.75 & 1.54 & 1.97 & 1.11 \\
\hline SOC & 1.87 & 1.20 & 1.76 & 0.96 & 2.28 & 1.65 & 1.64 & 1.03 \\
\hline ENTER & 3.30 & 1.55 & 5.20 & 1.30 & 2.98 & 1.88 & 5.84 & 0.85 \\
\hline PAE & 3.40 & 1.58 & 3.19 & 1.44 & 4.76 & 1.45 & 4.57 & 1.44 \\
\hline NAE & 1.33 & 0.71 & 1.23 & 0.76 & 2.62 & 1.41 & 2.46 & 1.28 \\
\hline ATT & 4.02 & 1.32 & 3.75 & 1.21 & 4.73 & 1.13 & 4.72 & 0.97 \\
\hline INT & 4.61 & 1.75 & 4.72 & 1.47 & 5.89 & 1.09 & 6.08 & 0.91 \\
\hline N. & $\mathbf{9 4}$ & & $\mathbf{6 7}$ & & $\mathbf{1 8}$ & & $\mathbf{9 1}$ & 2.25 \\
\hline
\end{tabular}

Appendix D. Results summary for structural modelab (Study 1)

\begin{tabular}{|c|c|c|c|c|c|c|c|c|c|}
\hline & \multicolumn{4}{|c|}{ Adoption } & \multicolumn{4}{|c|}{ Continuous usage } & \multirow{2}{*}{$\begin{array}{l}\text { Group } \\
\text { differences }\end{array}$} \\
\hline & $\begin{array}{l}\text { Path } \\
\text { coeff }\end{array}$ & $S E$ & $f^{2}$ & $q^{2}$ & $\begin{array}{l}\text { Path } \\
\text { coeff }\end{array}$ & $S E$ & $f^{2}$ & $q^{2}$ & \\
\hline $\mathrm{AT} \rightarrow \mathrm{INT}$ & $0.63 * * *$ & 0.05 & & & $0.41 * * *$ & 0.09 & & & $<0.05$ \\
\hline PAE $\rightarrow$ AT & $0.71 * * *$ & 0.05 & 1.08 & 0.57 & $0.34 * *$ & 0.11 & 0.12 & 0.05 & $<0.001$ \\
\hline PAE *PDT $\rightarrow$ AT & -0.10 & 0.06 & & & -0.05 & 0.08 & & & \\
\hline $\mathrm{NAE} \rightarrow \mathrm{AT}$ & 0.02 & 0.03 & & & $0.23^{*}$ & 0.11 & 0.06 & 0.03 & $<0.05$ \\
\hline NAE $*$ PDT $\rightarrow$ AT & 0.05 & 0.04 & & & -0.08 & 0.11 & & & \\
\hline PDT $\rightarrow$ AT & -0.06 & 0.05 & & & 0.05 & 0.06 & & & \\
\hline PURP $\rightarrow$ NAE & 0.10 & 0.09 & & & $0.37 * * *$ & 0.10 & 0.12 & 0.07 & $<0.05$ \\
\hline PURP $\rightarrow$ PAE & $0.45 * * *$ & 0.07 & 0.27 & 0.18 & $0.41 * * *$ & 0.10 & 0.19 & 0.13 & \\
\hline USAB $\rightarrow$ NAE & -0.03 & 0.06 & & & 0.10 & 0.07 & & & \\
\hline USAB $\rightarrow$ PAE & 0.08 & 0.06 & & & $0.18^{*}$ & 0.09 & 0.05 & 0.03 & \\
\hline MON $\rightarrow$ NAE & -0.01 & 0.05 & & & $-0.22 *$ & 0.11 & 0.05 & 0.03 & $<0.05$ \\
\hline MON $\rightarrow$ PAE & -0.03 & 0.04 & & & 0.00 & 0.07 & & & \\
\hline INTINT $\rightarrow$ NAE & -0.01 & 0.05 & & & $0.10^{*}$ & 0.09 & 0.01 & 0 & \\
\hline INTINT $\rightarrow$ PAE & -0.15 & 0.08 & & & $0.10^{*}$ & 0.09 & 0.01 & 0 & $<0.05$ \\
\hline SOC $\rightarrow$ NAE & $0.45^{* * *}$ & 0.08 & 0.18 & 0.14 & 0.01 & 0.07 & & & $<0.001$ \\
\hline SOC $\rightarrow$ PAE & $0.29 * * *$ & 0.07 & 0.13 & 0.09 & 0.05 & 0.07 & & & $<0.05$ \\
\hline
\end{tabular}




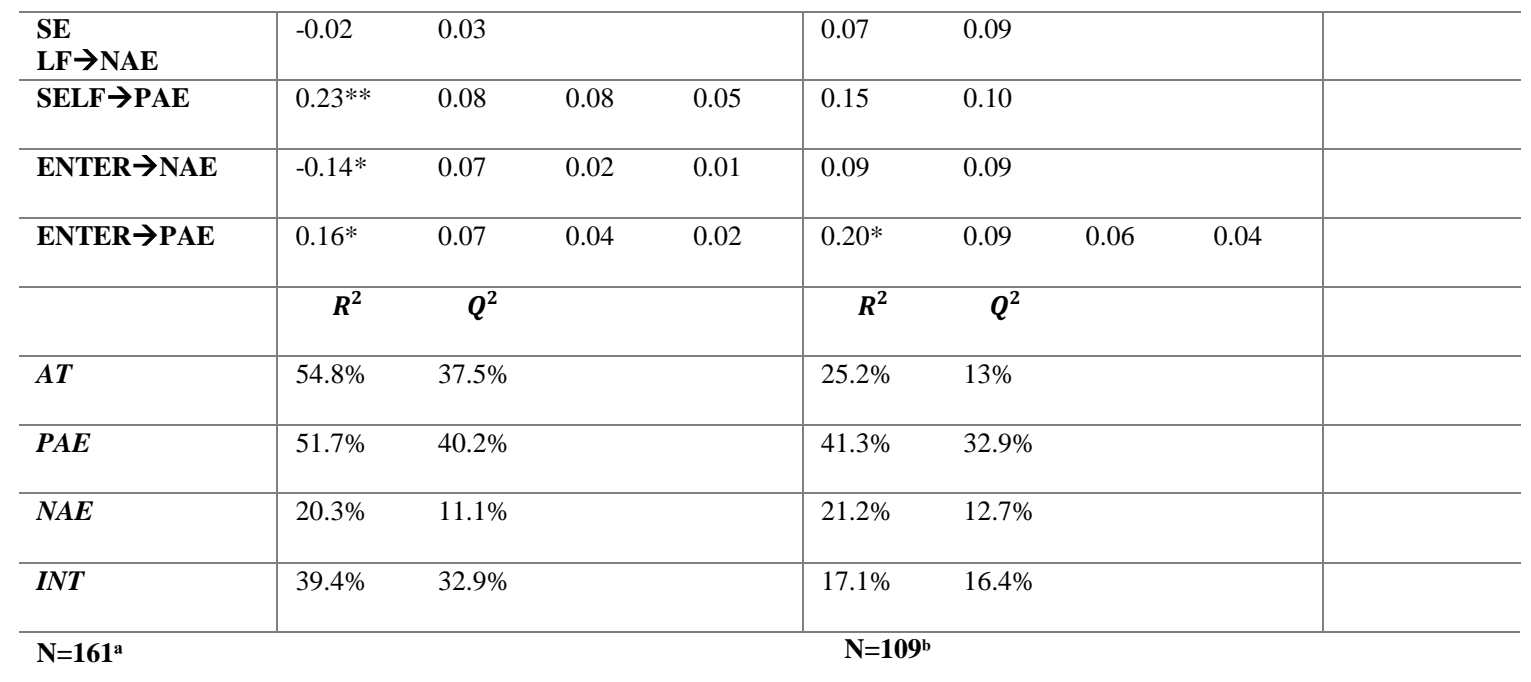

${ }^{\mathrm{c}}$ Only significant differences are reported

\section{Appendix E. Demographic statisticsa (Study 2)}

\begin{tabular}{llll}
\hline Gender & \multicolumn{3}{l}{ Nationality } \\
\hline Male & $87 \%$ & Italy & $29.1 \%$ \\
Female & $12 \%$ & Other Countries & $69.3 \%$ \\
Missing & $1 \%$ & Missing & $1.5 \%$ \\
\hline Age & & Education \\
\hline $18-27$ & $66 \%$ & High School/College & $53.4 \%$ \\
$28-35$ & $17.2 \%$ & 3-year Bachelor D. & $31.4 \%$ \\
$36-45$ & $10.5 \%$ & 5-year Master D. & $8.8 \%$ \\
$46-60$ & $4.9 \%$ & Degree (JD, MD) & $2.3 \%$ \\
61 or over & $0.8 \%$ & Other & $3.5 \%$ \\
Missing & $0.6 \%$ & Missing & $0.6 \%$ \\
\hline N=1106 & & &
\end{tabular}

\section{Appendix F. Descriptive statistics (Study 2)}

\begin{tabular}{|c|c|c|c|c|c|c|c|c|}
\hline \multirow[t]{2}{*}{ Construct } & \multicolumn{4}{|c|}{ Adoption } & \multicolumn{4}{|c|}{ Continuous usage } \\
\hline & \multicolumn{2}{|c|}{ Incremental } & \multicolumn{2}{|c|}{ Radical } & \multicolumn{2}{|c|}{ Incremental } & \multicolumn{2}{|c|}{ Radical } \\
\hline PURP & 3.21 & 1.38 & 3.38 & 1.23 & 5.29 & 1.22 & 3.89 & 1.39 \\
\hline USAB & 4.95 & 1.18 & 5.31 & 1.01 & 6.20 & 0.72 & 5.95 & 0.95 \\
\hline SELF & 2.48 & 1.26 & 3.07 & 1.47 & 3.46 & 1.64 & 2.96 & 1.55 \\
\hline INTINT & 4.22 & 1.55 & 3.90 & 1.59 & 5.16 & 1.59 & 3.13 & 1.51 \\
\hline SOC & 1.98 & 1.09 & 2.28 & 1.45 & 2.42 & 1.47 & 3.01 & 1.62 \\
\hline
\end{tabular}




\begin{tabular}{lcccccccc}
\hline PAE & 2.86 & 1.50 & 4.01 & 1.24 & 5.60 & 1.28 & 5.08 & 1.40 \\
\hline NAE & 1.21 & 0.66 & 1.29 & 0.59 & 3.23 & 1.55 & 2.48 & 1.36 \\
\hline ATT & 3.41 & 1.32 & 4.24 & 1.01 & 5.44 & 1.04 & 5.08 & 1.02 \\
\hline INT & 4.13 & 1.67 & 5.04 & 1.35 & 6.66 & 0.72 & 6.27 & 1.08 \\
\hline N. & $\mathbf{8 5}$ & & $\mathbf{1 0 4}$ & & $\mathbf{7 3 9}$ & & $\mathbf{1 7 8}$
\end{tabular}

Appendix G. Results summary for structural model ${ }^{\text {ab }}$ (Study 2)

\begin{tabular}{|c|c|c|c|c|c|c|c|c|c|}
\hline & \multicolumn{4}{|c|}{ Adoption } & \multicolumn{4}{|c|}{ Continuous usage } & \multirow{2}{*}{$\begin{array}{l}\begin{array}{l}\text { Group } \\
\text { differences }\end{array} \\
p \text {-value }\end{array}$} \\
\hline & $\begin{array}{l}\text { Path } \\
\text { coeff }\end{array}$ & $S E$ & $f^{2}$ & $q^{2}$ & $\begin{array}{l}\text { Path } \\
\text { coeff }\end{array}$ & $S E$ & $f^{2}$ & $q^{2}$ & \\
\hline $\mathbf{A T} \rightarrow \mathbf{I N T}$ & $0.64 * * *$ & 0.04 & & & $0.52 * * *$ & 0.03 & & & $<0.05$ \\
\hline PAE $\rightarrow$ AT & $0.62 * * *$ & 0.06 & 0.55 & 0.27 & $0.57 * * *$ & 0.03 & 0.48 & 0.21 & \\
\hline PAE*PDT $\rightarrow$ AT & -0.06 & 0.07 & & & -0.02 & 0.05 & & & \\
\hline $\mathbf{N A E} \rightarrow \mathbf{A T}$ & 0.00 & 0.08 & & & $0.18^{* * *}$ & 0.03 & & & $<0.05$ \\
\hline NAE $*$ PDT $\rightarrow$ AT & 0.10 & 0.10 & & & 0.02 & 0.05 & & & \\
\hline PDT $\rightarrow$ AT & 0.10 & 0.06 & & & -0.02 & 0.03 & & & \\
\hline PURP $\rightarrow$ NAE & 0.08 & 0.10 & & & $0.36^{* * * *}$ & 0.03 & 0.10 & 0.05 & \\
\hline PURP $\rightarrow$ PAE & $0.18^{*}$ & 0.08 & 0.04 & 0.03 & $0.33^{* * *}$ & 0.04 & 0.11 & 0.07 & \\
\hline USAB $\rightarrow$ NAE & $0.18 * *$ & 0.07 & 0.03 & 0.02 & $-0.08 *$ & 0.03 & 0.01 & 0.00 & $<0.001$ \\
\hline USAB $\rightarrow$ PAE & $0.18^{* *}$ & 0.07 & 0.04 & 0.03 & 0.04 & 0.03 & & & \\
\hline MON $\rightarrow$ NAE & -0.06 & 0.07 & & & 0.05 & 0.03 & & & \\
\hline MON $\rightarrow$ PAE & 0.06 & 0.06 & & & $0.17 * * *$ & 0.03 & 0.16 & 0.02 & \\
\hline INTINT $\rightarrow$ NAE & 0.08 & 0.09 & & & 0.00 & 0.03 & & & \\
\hline INTINT $\rightarrow$ PAE & 0.02 & 0.08 & & & -0.06 & 0.03 & & & \\
\hline SOC $\rightarrow$ NAE & $0.16^{*}$ & 0.07 & 0.02 & 0.02 & $0.14 * * *$ & 0.04 & 0.02 & 0.01 & \\
\hline SOC $\rightarrow$ PAE & $0.15^{*}$ & 0.07 & 0.03 & 0.02 & $0.06^{*}$ & 0.03 & 0.02 & 0.01 & \\
\hline SELF $\rightarrow$ NAE & 0.13 & 0.08 & & & 0.00 & 0.04 & & & \\
\hline SELF $\rightarrow$ PAE & $0.17^{*}$ & 0.08 & 0.03 & 0.02 & $0.14 * * *$ & 0.03 & 0.02 & 0.01 & \\
\hline ENTER $\rightarrow$ NAE & -0.06 & 0.08 & & & $0.13^{* * *}$ & 0.03 & 0.02 & 0.01 & \\
\hline \multirow[t]{2}{*}{ ENTER $\rightarrow$ PAE } & $0.28 * * *$ & 0.07 & 0.09 & 0.06 & $0.24 * * *$ & 0.04 & 0.07 & 0.05 & \\
\hline & $R^{2}$ & $Q^{2}$ & & & $R^{2}$ & $Q^{2}$ & & & \\
\hline$A T$ & $47.1 \%$ & $30.4 \%$ & & & $44.8 \%$ & $25.9 \%$ & & & \\
\hline$P A E$ & $37.7 \%$ & $28 \%$ & & & $40.6 \%$ & $30.1 \%$ & & & \\
\hline$N A E$ & $11.6 \%$ & $6.5 \%$ & & & $21.4 \%$ & $12.5 \%$ & & & \\
\hline INT & $41.2 \%$ & $35.6 \%$ & & & $27.1 \%$ & $24.2 \%$ & & & \\
\hline
\end{tabular}


This is a post-peer-review, pre-copyedit version of an article published in Journal of Consumer Marketing. The final authenticated version is available online at:

https://doi.org/10.1108/JCM-06-2016-1860 